Original Research Paper

\title{
Optimization, Characterization and Antioxidant Activities of Selenized Polysaccharides from Hypsizygus marmoreus
}

\author{
Ting Liu, Xue Jiang, Wei Wang and Bing Xu \\ School of Biology and Food Engineering, Changshu Institute of Technology, Changshu 215500, PR China
}

\author{
Article history \\ Received: 15-05-2019 \\ Revised: 21-07-2019 \\ Accepted: 05-07-2019 \\ Corresponding Author: \\ Bing Xu \\ School of Biology and Food \\ Engineering, Changshu \\ Institute of Technology, \\ Changshu 215500, PR China \\ Email: Xubing@cslg.cn
}

\begin{abstract}
In this study, hypsizygus marmoreus was used as raw material to extract polysaccharides by hot water extraction method. Preparation technology of Selenized Polysaccharides from Hypsizygus marmoreus (SPHM) and its antioxidant activities were investigated. Chelation rate was selected as the index, effects of initial concentration of sodium selenite $(\mathrm{mg} / \mathrm{mL})$, the mass ratio of polysaccharide to sodium selenite, chelation time and $\mathrm{pH}$ on the chelation rate was investigated by single factor test. Response surface method was used to optimize the preparation technology of SPHM. The preliminary structure characterization of Polysaccharides from Hypsizygus marmoreus (PHM) and SPHM was performed by infrared spectroscopy and scanning electron microscopy. The antioxidant activities of SPHM were studied by the scavenging effect of 1,1-Diphenyl-2-picrylhydrazyl radical 2,2-Diphenyl-1(2,4,6-trinitrophenyl) Hydrazyl (DPPH) and hydroxyl radical. The results showed that the optimum preparation technology of SPHM was as follows: the initial concentration of sodium selenite was $7.95(\mathrm{mg} / \mathrm{mL})$, the mass ratio of polysaccharide to sodium selenite was $6.11: 1(\mathrm{mg} / \mathrm{mg})$, chelation time was $6.89 \mathrm{~h}$ and $\mathrm{pH}$ was 5.11. Under the optimum conditions, chelate rate was $10.36 \%$. Infrared spectroscopy and scanning electron microscopy analysis showed that selenium ions successfully combined with PHM and the surface structure of PHM and SPHM was different. Compared with HPM, the antioxidant activities of SPHM enhanced.
\end{abstract}

Keywords: SPHM, Sodium Selenite, Chelation, Antioxidant

\section{Introduction}

Se is one of the essential trace elements in human life activities. Se exhibits antitumor activity, improves immunity and has antiaging properties (Rayman, 2000). The main two forms of Se generally present in nature are inorganic Se and organic Se. Malgorzata et al. (2012) reported that organic Se compounds have the advantage of mild toxicity, easy absorption and high bioavailability compared with inorganic Se. To reduce the original toxicity of Se, we combined the Se and polysaccharide. Chelate has the Se's advantages and also has the advantages of polysaccharide. Therefore, chelate has antiviral and antitumor properties and is easily absorbed and utilized by the bodies. The chelate's biological activity is generally higher than that of polysaccharide and inorganic Se (Zhu et al., 2016). On the basis of the present condition, synthetic Se polysaccharides, such as Enteromorpha selenide (Haitao et al., 2018), Tussilago farfara L. Se (Gaiyan et al., 2016), Cucurbita moschata (Duch. ex Lam.) Duch. ex Poiret Se (Selvi et al., 2012), Punica granatum L. bark Se (Gharzouli et al., 1999), Taraxacum mongolicum Hand-Mazz selenide (Sui et al., 2004) and Lilium brownii var. viridulum Se polysaccharide (Li et al., 2010), showed that the bioactivities of Se polysaccharides, such as bacteriostatic, antioxidant and antitumor, were improved to some extent compared with unselenized polysaccharides.

Hypsizygus marmoreus is affiliated to the basidiomycetes, hymenomycetes, agaricales, tricholomataceae and hypsizigus. H. marmoreus is also known as seafood mushroom with high nutritional value (Li et al., 2009). Polysaccharide is one of the main components of H. marmoreus. Studies on PHM mainly focused on biological activities, such as antitumor (Yasukawa et al., 1994), immune enhancer (Zhang et al., 2015a), antivirus (Song et al., 2013), antioxidation (Liu et al., 2018; Huang et al., 2015) and antibacterial (Xing et al., 2007) properties through molecular structural characteristic (Lingyun, 2014), extraction (Zhang et al., 2017a; 2017b; Harada et al., 2005) and component analyses (Tao et al., 2007) to date. However, the study on the chelation of PHM and microelement has not been reported in the literature. 
This study, according to the modification of selenized polysaccharide, it showed improved biological activity and bioavailability by utilizing the response surface analysis method to optimize the chelating process of SPHM. We also studied the ant oxidative activity of PHM before and after chelation. The effect of selenization on the antioxidant activity of PHM was also discussed. Considering the added value of $H$. marmoreus, this study also aims to serve as a theoretical reference for the development of the emerging antioxidant food of SPHM.

\section{Materials and Methods}

\section{Materials and Instruments}

H. marmoreus was provided by the Kunshan Zhengxing Edible Fungus Co., Ltd. DPPH was also obtained from the Shenzhen Xinbosheng Biotechnology Co., Ltd. The reagents that were used in this experiment, such as sodium selenite, hydrogen peroxide and potassium sodium tartrate were all of analytical grade.

A small-pulverizer high-speed engine was from Shandong Weinuo Medical Equipment Manufacturing Co., Ltd. HH-2 intelligent digital display constant temperature water bath was provided by the Changzhou Guohua Electric Co., Ltd. The 722-type digital visible spectrophotometer was provided by Shanghai Optical Instrument Factory Co., Ltd. IRTracer-100 Fu Li Leaftransformed infrared spectrometer was provided by Japan Shimadzu Corporation. RE-52AA rotary evaporator was from the Beijing Chengmeng Weiye Technology Co., Ltd. SHB-B95 circulating water type multipurpose vacuum pump was provided by Zhengzhou Century Shuangke Experimental Instrument Co., Ltd. CR22GII high-speed refrigerated centrifuge was provided by the Hitachi Company, Japan. Alpha 1-2 LD plus vacuum freeze dryer was provided by CHRIST Company, Germany. ZEISS SIGMA thermal field emission scanning electron microscope was provided by Carl Zeiss Company, Germany.

\section{Experimental}

\section{PHM Preparation}

H. marmoreus passed through 60 meshes to remove the impurities, drying $\left(30^{\circ} \mathrm{C}, 24 \mathrm{~h}\right)$, crushing and sieving through 60 meshes. Then, the H. marmoreus powder was obtained. Afterward, $100 \mathrm{~g}$ of $H$, marmoreus powder was mixed with $2000 \mathrm{~mL}$ of distilled water and extracted at $90^{\circ} \mathrm{C}$ for $5 \mathrm{~h}$. The precipitate was removed by centrifugation $(4000 \mathrm{r} / \mathrm{min}, 15 \mathrm{~min})$ and the clear supernatant extract was concentrated at $70^{\circ} \mathrm{C}$ for $3 \mathrm{~h}$ (Zhang et al., 2015b). Then, the protein was removed by sevag method (Kumar and Satheesan, 2010) and the supernate was collected after centrifugation, followed by addition of three times the volume of $85 \%$ ethanol. Then, the supernate was centrifuged (4000 r/min, $20 \mathrm{~min})$ after ethanol precipitation for $24 \mathrm{~h}$ at $4{ }^{\circ} \mathrm{C}$. Cryodesiccation technique was also applied to the precipitate to obtain the PHM.

\section{SPHM Preparation}

We took 0.1-0.3 g PHM, added 5-15 mL of $\mathrm{HNO}_{3}$ solution (volume fraction of $0.5 \%$ ), heated and stirred until the polysaccharide was completely dissolved. A certain mass ratio of sodium selenite was also added, stirred at $70^{\circ} \mathrm{C}$ for $6-8 \mathrm{~h}$ under a certain $\mathrm{pH}$ condition, cooled and centrifuged at $3000 \mathrm{r} / \mathrm{min}$ for $5 \mathrm{~min}$. Then, the supernatant was placed in a bag filter (interception molecular weight of $3500 \mathrm{Da}$ ). Dialysis was performed using flowing water for $24 \mathrm{~h}$. Then, we took a small amount of dialysate and checked for residual sodium selenite by adding ascorbic acid until the dialysate color changed from blood red. The dialysate was cryodesiccated to obtain a SPHM.

\section{Chelating Rate Calculation}

The standard mother liquor of sodium selenite should be accurately prepared at concentration of $1 \mathrm{mg} / \mathrm{mL}$. Then, the standard liquor concentrations of $0,4,8,12$, 16 and $20 \mathrm{~mL}$ were measured separately and added with $10 \mathrm{~mL}$ of ultrapure water. The mass concentrations of sodium selenite were $0,0.4,0.8,1.2,1.6$ and $20 \mathrm{mg} / \mathrm{mL}$ and that of Se was measured by the flame atomic absorption method. The abscissa and ordinate were the mass concentration and absorbance of Se, respectively. We also drew a standard curve. We obtained the regression equation $\mathrm{Y}=0.2569 \mathrm{X}+0.0375, \mathrm{R} 2=0.9826$, where $\mathrm{Y}$ is the absorbance; and $\mathrm{X}$ is the mass $\mathrm{Se}$ concentration $(\mathrm{mg} / \mathrm{mL}$ ) (Xue et al., 2009). The chelation rate was calculated using the following equation:

Chelation rate $(\%)=\left[\left(C_{0}-C\right) / C_{0}\right] \times 100$,

where, $C_{0}$ is the mass Se concentration in the solution before chelation $(\mathrm{mg} / \mathrm{mL})$ and $C$ is the mass Se concentration in the solution after chelation $(\mathrm{mg} / \mathrm{mL})$.

\section{Single Factor Experiment on SPHM Preparation}

\section{Effect of Initial Mass Sodium Selenite Concentration on Chelating Rate}

We formulated sodium selenite solution with the initial mass concentrations of 3, 4, 5, 6, 7 and $8 \mathrm{mg} / \mathrm{mL}$ with PHM (dissolved in $50 \mathrm{~mL}$ of $0.5 \% \mathrm{HNO}_{3}$ solution) and the sodium selenite mass ratio $(\mathrm{mg} / \mathrm{mg})$ was $4: 1$. Then, we added PHM and the reaction was stirred at $70^{\circ} \mathrm{C}$ for $7 \mathrm{~h}$ at $\mathrm{pH}$ of 5 to determine the optimum initial sodium selenite concentration. 


\section{Effect of Chelating Time on Chelating Rate}

We removed the sodium selenite solution at a concentration of $4 \mathrm{mg} / \mathrm{mL}$ and added 4 to 1 by mass ratio $\left(\mathrm{mg} / \mathrm{mg}\right.$ ) of the PHM (dissolved in $50 \mathrm{~mL}$ of $0.5 \% \mathrm{HNO}_{3}$ solution) to sodium selenite. PHM was chelated for 4,5 , $6,7,8$ and $9 \mathrm{~h}$ at the $\mathrm{pH}$ of 5 and $70^{\circ} \mathrm{C}$ to determine the optimal chelating time.

Effect of Mass Ratio of PHM to Sodium Selenite Referred to as Mass Ratio on Chelating Rate

We removed the sodium selenite solution at a concentration of $4 \mathrm{mg} / \mathrm{mL}$ at the mass ratios $(\mathrm{mg} / \mathrm{mg})$ of PHM (dissolved in a volume fraction of $0.5 \% \mathrm{HNO}_{3}$ solution $50 \mathrm{~mL}$ ) and sodium selenite of 3: 1, 4: 1, 5: 1, 6: 1, 7: 1 and 8: 1 We added the PHM and stirred at $70^{\circ} \mathrm{C}$ for $7 \mathrm{~h}$ at $\mathrm{pH} 5$ while the reaction progressed. Consequently, the proper mass ratio of $H$. marmoreus and sodium selenite was determined.

\section{Effect of $\mathrm{pH}$ on Chelating Rate}

We removed the sodium selenite solution at a concentration of $4 \mathrm{mg} / \mathrm{mL}$ and added PHM 4 to 1 by mass ratio $(\mathrm{mg} / \mathrm{mg}$ ) of the PHM (dissolved in $50 \mathrm{~mL}$ of a $0.5 \%$ $\mathrm{HNO}_{3}$ solution) and sodium selenite and agitated at the $\mathrm{pH}$ levels of $3,4,5,6,7$ and 8 at $70^{\circ} \mathrm{C}$ for $7 \mathrm{~h}$ to determine the optimum $\mathrm{pH}$.

\section{Response Surface Test}

According to the results of the single factor experiment, we used the design principle of Box-Benhnken's Central Combination Experiment with chelating rate as the index to design the regression equation of the initial mass concentration, mass ratio, chelation time and $\mathrm{pH}$ of the sodium selenite and fit the relationship between each factor and the response values. We also used the Design-Expert 8.0.6 software to conduct response surface analysis and obtain the optimal preparation process of SPHM.

\section{Infrared Characterization of PHM and SPHM}

We took appropriate amount of dried PHM and SPHM powder and mixed with appropriate amount of $\mathrm{KBr}$. The infrared spectrum was scanned at the wave number (WN) range of $4000-400 \mathrm{~cm}^{-1}$. The infrared spectra of the polysaccharide and chelate were also determined.

\section{Scanning Electron Microscopy Analysis of PHM and Se Chelate}

We took a certain amount of dried PHM and SPHM that adhered to the specimen holder, blew the floating sample out and then sprayed gold. The appearance and morphology of the specimen were observed at the magnification of $2000 \times$ and a high pressure of $20.00 \mathrm{kV}$ by using the ZEISS thermal field emission electron microscope.

\section{Determination of Antioxidant Activity of PHM and Se Chelate}

\section{Determination of DPPH Free Radical Scavenging Ability (Suja et al., 2004)}

We accurately weighed $0.0128 \mathrm{~g}$ free radicals of DPPH, added $70 \%$ ethanol and then constant volume in a $50 \mathrm{~mL}$ volumetric flask, shook and stored in the dark after it is completely dissolved. We transferred $2 \mathrm{~mL}$ of DPPH solution into the comparison tubes, added $1 \mathrm{~mL}$ of different mass concentrations $(0.2,0.4,0.6,0.8$ and 1.0 $\mathrm{mg} / \mathrm{mL}$ ) of PHM and SPHM solution and reacted at room temperature in the dark for $30 \mathrm{~min}$. Distilled water was also added for blank zero correction. The absorption was measured at the wavelength of $517 \mathrm{~nm}$ and the clearance rate of DPPH free radical was calculated as follows:

Clearance rate $(\%)=\left[\left(\mathrm{A}_{\mathrm{i}}-\mathrm{A}_{\mathrm{j}}\right) / \mathrm{A}_{0}\right] \times 100$,

where, $A_{i}$ consists of $2 \mathrm{~mL}$ of DPPH $+1 \mathrm{~mL}$ of PHM solution (SPHM solution); $A_{j}$ comprises $2 \mathrm{~mL}$ PHM solution (SPHM solution) $+1 \mathrm{~mL}$ ethanol solution with the volume fraction of $70 \%$; $A_{0}$ is composed of $2 \mathrm{~mL}$ of $\mathrm{DPPH}+1$ of $\mathrm{mL}$ ethanol solution and the volume fraction was $70 \%$.

\section{OH Radical Scavenging Ability Determination (Hirayama and Yida, 1997)}

We added ED $1 \mathrm{~mL}$ of $\mathrm{FeSO}_{4}$ solution $(9 \mathrm{mmol} / \mathrm{L}), 2$ $\mathrm{mL}$ of salicylic acid-ethanol solution $(9 \mathrm{mmol} / \mathrm{L}), 2 \mathrm{~mL}$ of different mass concentrations $(0.2,0.4,0.6,0.8$ and 1.0 $\mathrm{mg} / \mathrm{mL}$ ) of polysaccharide/SPHM solution and $2 \mathrm{~mL}$ of $\mathrm{H}_{2} \mathrm{O}_{2}$ solution $(8.8 \mathrm{mmol} / \mathrm{L})$ to the colorimetric tube. The solution was subjected to water bath at $37^{\circ} \mathrm{C}$ for $30 \mathrm{~min}$. The sample absorbance was measured at the wavelength of $510 \mathrm{~nm}$ with distilled water used for zero correction. The clearance rate of the $\mathrm{OH}$ radicals was calculated as follows:

Clearance $\operatorname{rate}(\%)=\left[\left(\mathrm{A}_{0}-\mathrm{A}_{\mathrm{j}}\right) / \mathrm{A}_{0}\right] \times 100$,

where, $A_{0}$ is the absorbance of the blank control solution and $A_{j}$ is the absorbance of the sample group.

\section{Results and Discussion}

Effects of Single Factor on Chelating Rate

Effect of Initial Mass Sodium Selenite Concentration on Chelating Rate 
The effects of the initial mass sodium selenite concentration on the chelating rate are shown in Fig. 1. Figure 1 shows the increasing chelating rates of PHM and Se along with the mass sodium selenite concentration. When the mass sodium selenite concentration was 7 $\mathrm{mg} / \mathrm{mL}$, the chelating rate reached the maximum. Then, the chelating rate began to decrease possibly because the chelation is incomplete because of the extremely low initial Se concentration. However, when the concentration was exceedingly high, the reaction mixture was saturated. By contrast, sodium selenite addition hindered the chelation reaction. Therefore, the optimum initial mass sodium selenite concentration was $6 \mathrm{mg} / \mathrm{mL}$.

\section{Effects of Chelation Time on Chelating Rate}

The effects of chelation time on chelating rate are shown in Fig. 2. Figure 2 shows that when the chelation time was extended from $4 \mathrm{~h}$ to $9 \mathrm{~h}$, the chelating rate tended to increase first and then slowly decrease and the latter tended to be stable. When the chelation time was $6 \mathrm{~h}$, the chelating rate reached the maximum. Thus, the optimal chelation time is $6 \mathrm{~h}$.

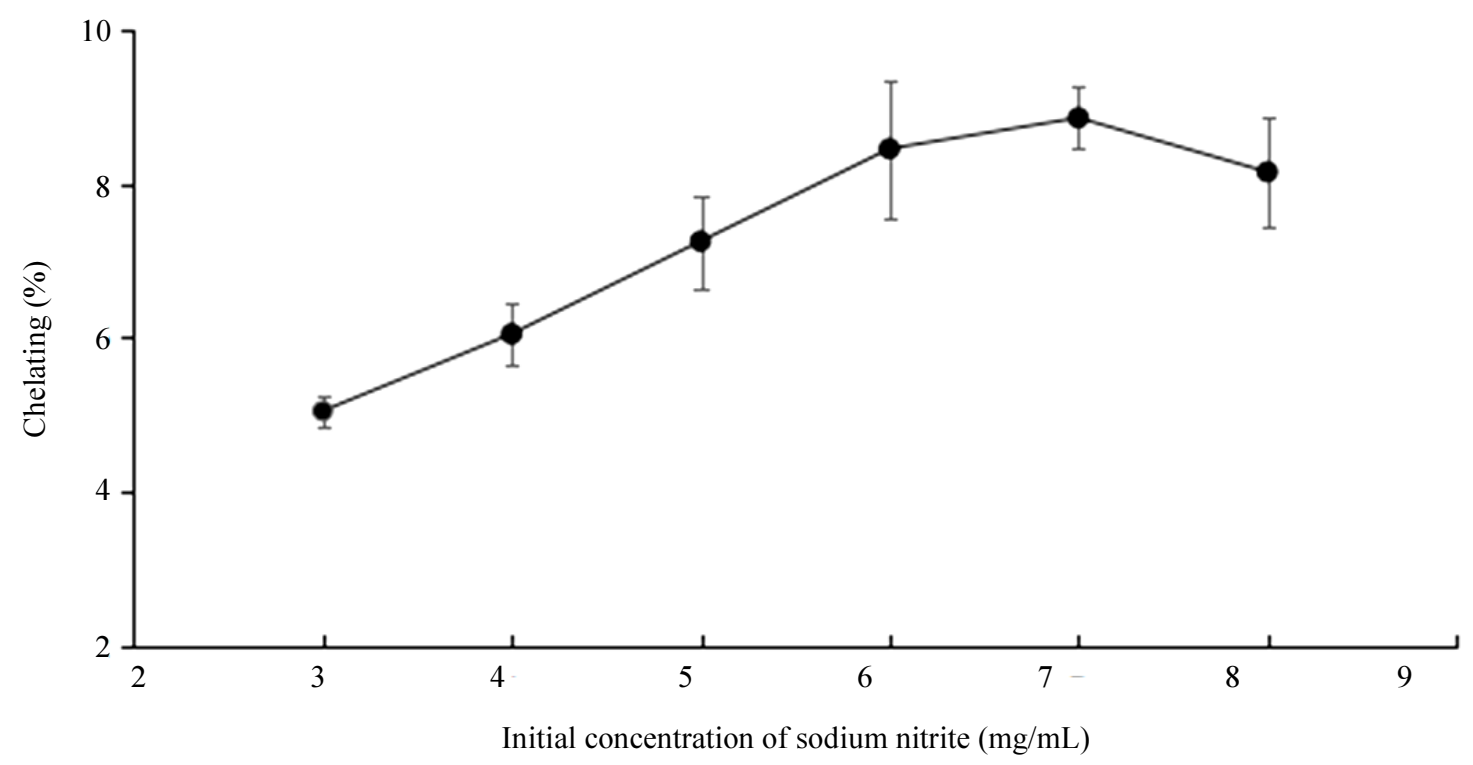

Fig. 1: Effect of initial mass sodium selenite concentration on chelation rate

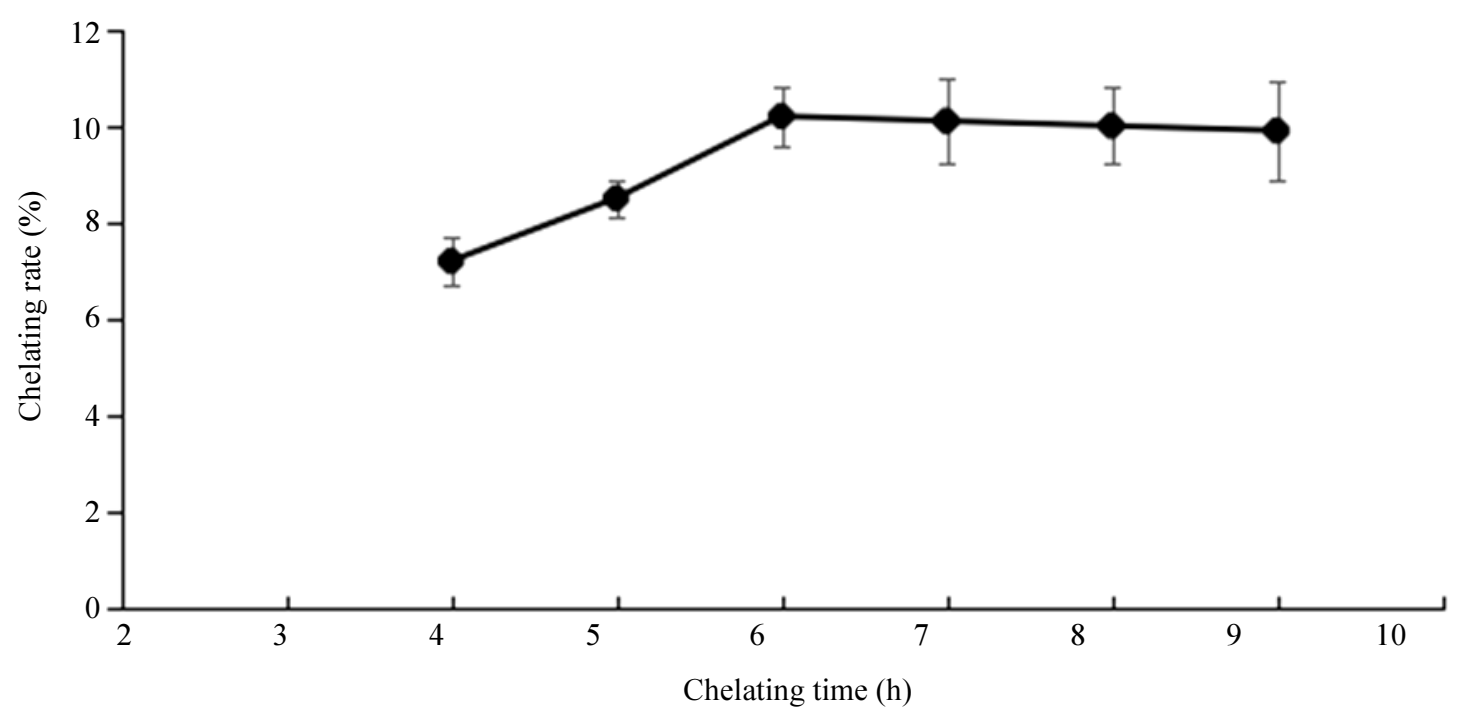

Fig. 2: Effect of chelation time on chelation rate 


\section{Effects of Mass Ratio on Chelating Rate}

The effects of the mass ratio of PHM to sodium selenite on the chelating rate are shown in Fig. 3. As shown in Fig. 3, along with the PHM, the mass ratio $(\mathrm{mg} / \mathrm{mg})$ to sodium selenite increased first and then decreased. When the mass ratio was $6: 1$, the chelating rate reached the maximum. Therefore, the most appropriate mass ratio of the PHM to sodium selenite was $6: 1$. On the basis of this condition, we combined PHM with other optimization conditions and obtained the final chelating rate by taking the average value through many experiments.

\section{Effects of $\mathrm{pH}$ on Chelating Rate}

The effect of $\mathrm{pH}$ on the chelating rate is shown in Fig. 4. Figure 4 shows the chelating rate of PHM and sodium selenite with increased $\mathrm{pH}$, thereby showing a trend that increased first and then decreased. When the $\mathrm{pH}$ was 5 , the chelating rate reached the maximum. This result may be due to the fact that the reaction liquid $\mathrm{pH}$ has a certain influence on the strength of Se ions.

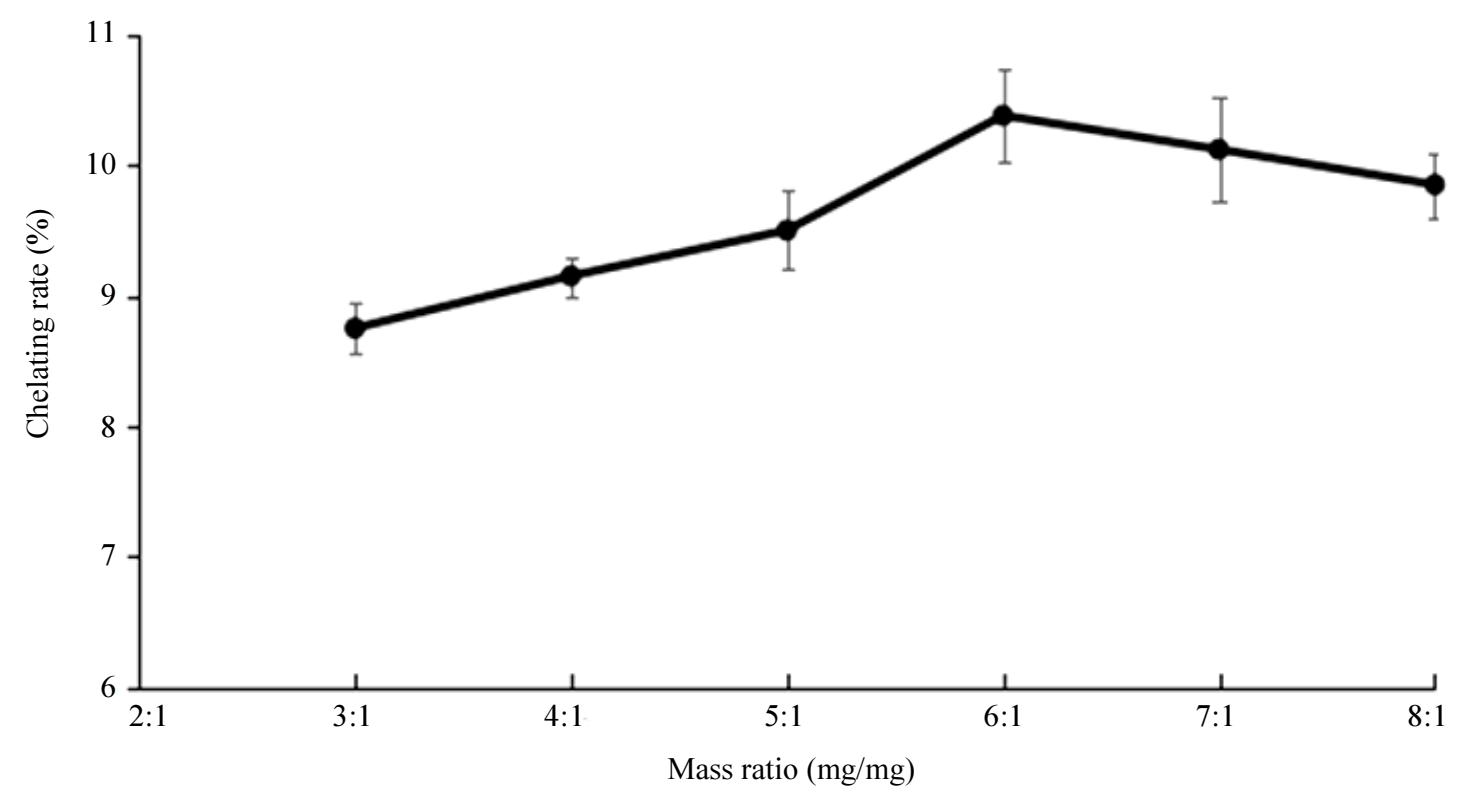

Fig. 3: Effect of mass ratio on chelation rate

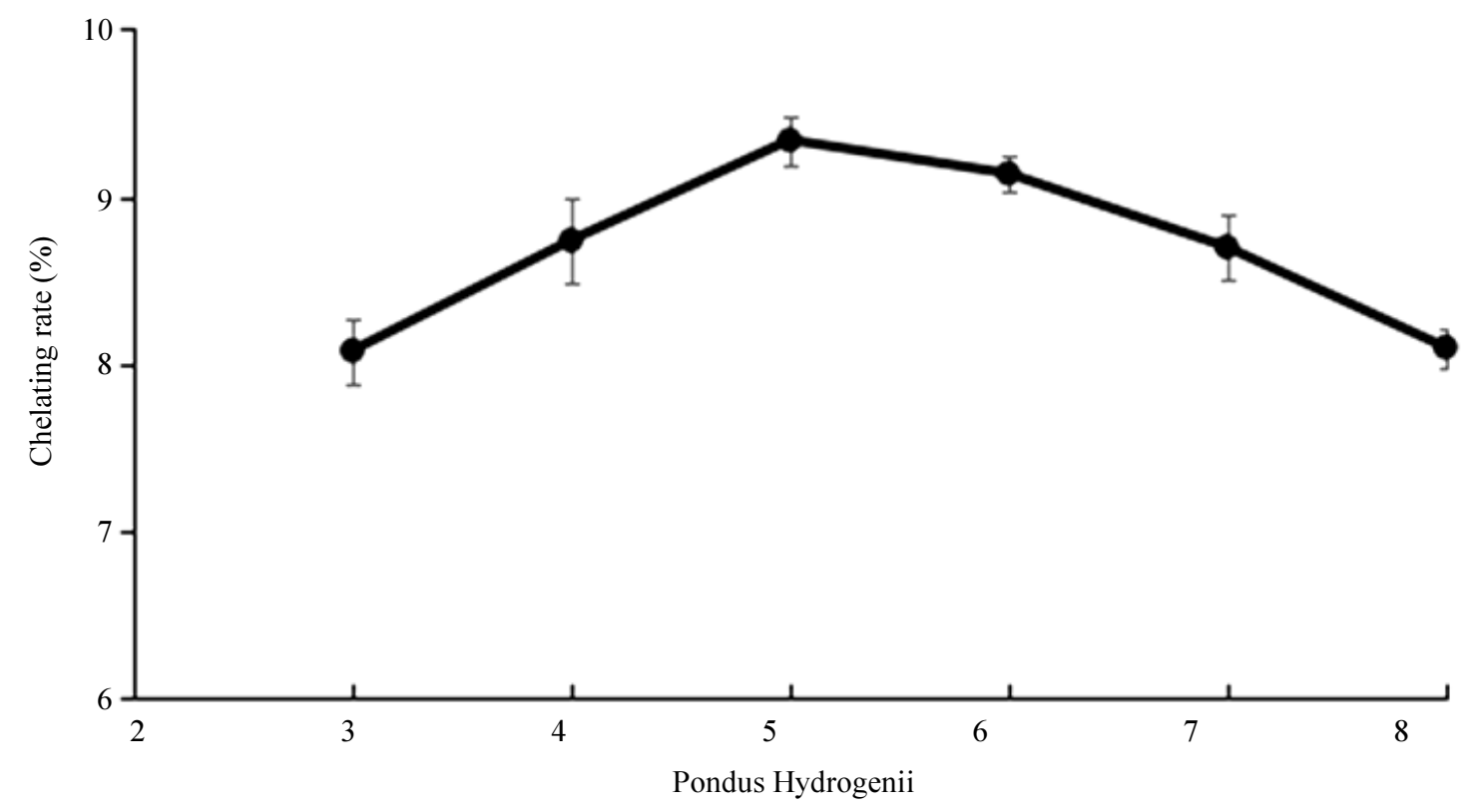

Fig. 4: Effect of $\mathrm{pH}$ on chelation rate 
If the $\mathrm{pH}$ is extremely high, then the anion in the solution will compete with the active group of the PHM, thereby hindering chelate formation. If the $\mathrm{pH}$ is extremely small, then the $\mathrm{H}$ ions generated in the reaction solution increase, thereby leading to incompletely chelated $\mathrm{Se}$ ions, thereby resulting in reduced chelation rate (Schmidbaur and Mitschke, 1971). Therefore, the optimum $\mathrm{pH}$ for chelation is 5 .

\section{Optimization of Chelation of $\boldsymbol{H}$. marmoreus Polysaccharide and Se}

\section{Response Model Establishment and Analysis}

According to the results of single factor experiments, the chelation rate was the index. The experimental design factors and the horizontal values are shown in
Table 1. The consequence of the experimental design of Box-Behnken and the chelating rate response values are shown in Table 2 . The results of variance analysis are shown in Table 3. We used Design-Expert 8.0.6 to analyze the data in Table 2 . The chelating rate (Y) to the initial mass concentration (A), mass ratio (B), chelation time (C) and $\mathrm{pH}$ (D) of sodium selenite were obtained after regression analysis of each factor.

The regression equation:

$$
\begin{aligned}
& \mathrm{Y}=-55.10950+0.44533 \mathrm{~A}+11.69767 \mathrm{~B}+2.08433 \mathrm{C}+7 \\
& 15167 \mathrm{D}++0.010000 \mathrm{AB}+0.66250 \mathrm{AC}++0.79750 \mathrm{AD}+0.04 \\
& 0000 \mathrm{BC}-0.13500 \mathrm{BD}+0.28750 \mathrm{CD}-0.57008 \mathrm{~A}^{2}-0.90258 \mathrm{~B}^{2} \\
& -0.67758 \mathrm{C}^{2}-1.35258 \mathrm{D}^{2}
\end{aligned}
$$

\begin{tabular}{|c|c|c|c|c|}
\hline \multirow[b]{2}{*}{ Level } & \multicolumn{4}{|l|}{ Factor } \\
\hline & $\begin{array}{l}\text { A } \\
\text { Initial mass } \\
\text { Concentration of sodium } \\
\text { Selenite }(\mathrm{mg} / \mathrm{mL})\end{array}$ & $\begin{array}{l}\text { B } \\
\text { Mass ratio } \\
(\mathrm{mg} / \mathrm{mg})\end{array}$ & $\begin{array}{l}\mathrm{C} \\
\text { Chelating time }(\mathrm{h})\end{array}$ & $\begin{array}{l}\mathrm{D} \\
\mathrm{pH}\end{array}$ \\
\hline-1 & 6 & $5: 1$ & 5 & 4 \\
\hline 0 & 7 & $6: 1$ & 6 & 5 \\
\hline 1 & 8 & $7: 1$ & 7 & 6 \\
\hline
\end{tabular}

\begin{tabular}{|c|c|c|c|c|c|}
\hline Test number & A & $\mathrm{B}$ & $\mathrm{C}$ & $\mathrm{D}$ & Chelation rate $(\%)$ \\
\hline 1 & 0 & 0 & 0 & 0 & 10.13 \\
\hline 2 & 0 & -1 & 0 & 1 & 7.39 \\
\hline 3 & 1 & 0 & 0 & -1 & 7.42 \\
\hline 4 & 0 & -1 & -1 & 0 & 7.73 \\
\hline 5 & -1 & 0 & 1 & 0 & 7.81 \\
\hline 6 & -1 & -1 & 0 & 0 & 7.18 \\
\hline 7 & 1 & -1 & 0 & 0 & 8.92 \\
\hline 8 & -1 & 0 & 0 & -1 & 8.77 \\
\hline 9 & -1 & 0 & -1 & 0 & 8.73 \\
\hline 10 & 0 & 0 & 0 & 0 & 10.09 \\
\hline 11 & 0 & 0 & 1 & -1 & 7.73 \\
\hline 12 & 0 & 0 & 0 & 0 & 10.08 \\
\hline 13 & -1 & 0 & 0 & 1 & 7.21 \\
\hline 14 & 0 & 1 & 0 & -1 & 8.32 \\
\hline 15 & 0 & 0 & 0 & 0 & 9.41 \\
\hline 16 & 0 & 1 & 0 & 1 & 8.15 \\
\hline 17 & 0 & 0 & 1 & 1 & 8.91 \\
\hline 18 & 0 & 1 & 1 & 0 & 9.26 \\
\hline 19 & 0 & 0 & -1 & 1 & 7.59 \\
\hline 20 & 0 & -1 & 1 & 0 & 8.11 \\
\hline 21 & 0 & 0 & -1 & -1 & 7.56 \\
\hline 22 & 1 & 0 & -1 & 0 & 8.32 \\
\hline 23 & 0 & 1 & -1 & 0 & 8.72 \\
\hline 24 & -1 & 1 & 0 & 0 & 8.07 \\
\hline 25 & 1 & 1 & 0 & 0 & 9.85 \\
\hline 26 & 0 & -1 & 0 & -1 & 7.02 \\
\hline 27 & 1 & 0 & 0 & 1 & 9.05 \\
\hline 28 & 0 & 0 & 0 & 0 & 10.27 \\
\hline 29 & 1 & 0 & 1 & 0 & 10.05 \\
\hline
\end{tabular}

Table 1: Factors and levels designed for response surface analysis

Table 2: Box-Behnken design with response values for chelation rate 
Table 3: Analysis of variance for regression model

\begin{tabular}{|c|c|c|c|c|c|c|}
\hline Source & Sum of squares & Degrees of freedom & Mean square & F value & $P$ value & significant \\
\hline Model & 27.20 & 14 & 1.94 & 14.32 & $<0.0001$ & $* *$ \\
\hline A & 2.84 & 1 & 2.84 & 20.96 & 0.0004 & $* *$ \\
\hline B & 3.02 & 1 & 3.02 & 22.27 & 0.0003 & $* *$ \\
\hline $\mathrm{C}$ & 0.86 & 1 & 0.86 & 6.37 & 0.0243 & $*$ \\
\hline $\mathrm{D}$ & 0.18 & 1 & 0.18 & 1.35 & 0.2654 & \\
\hline $\mathrm{AB}$ & $4 \times 10^{-4}$ & 1 & $4 \times 10^{-4}$ & $2.949 \times 10^{-3}$ & 0.9575 & \\
\hline $\mathrm{AC}$ & 1.76 & 1 & 1.76 & 12.95 & 0.0029 & $*$ \\
\hline $\mathrm{AD}$ & 2.54 & 1 & 2.54 & 18.76 & 0.0007 & $* *$ \\
\hline $\mathrm{BC}$ & $6.4 \times 10^{-3}$ & 1 & $6.4 \times 10^{-3}$ & 0.047 & 0.8312 & \\
\hline BD & 0.073 & 1 & 0.073 & 0.54 & 0.4756 & \\
\hline $\mathrm{CD}$ & 0.33 & 1 & 0.33 & 2.44 & 0.1408 & \\
\hline$A^{2}$ & 2.11 & 1 & 2.11 & 15.54 & 0.0015 & $*$ \\
\hline$B^{2}$ & 5.28 & 1 & 5.28 & 38.96 & $<0.0001$ & $* *$ \\
\hline $\mathrm{C}^{2}$ & 2.98 & 1 & 2.98 & 21.96 & 0.0004 & $* *$ \\
\hline $\mathrm{D}^{2}$ & 11.87 & 1 & 11.87 & 87.50 & $<0.0001$ & $* *$ \\
\hline Residual error & 1.90 & 14 & 0.14 & & & \\
\hline Lack of fit & 1.45 & 10 & 0.14 & 1.28 & 0.4379 & \\
\hline Pure error & 0.45 & 4 & 0.11 & & & \\
\hline Sum total & 29.10 & 28 & & & & \\
\hline
\end{tabular}

(Note: $P<0.05$, the difference is significant; $P<0.001$, the difference is extremely significant)

According to variance analysis results in Table 3, the model selected in this experiment was extremely significant $(\mathrm{P}<0.001)$ and the equations' lack-of-fit was insignificant $(\mathrm{P}=0.4379>0.05)$. This finding indicated that the unknown factors had low influence on the test. This model was suitable for this experiment, with the $\mathrm{R}^{2}$ $=0.9347$, thereby indicating that the model had good goodness of fit and can be used for preliminary analysis and prediction of the Se preparation in PHM. In addition to $\mathrm{D}$, the linear effects of the three factors on the chelation degree was significant $(\mathrm{P}<0.05$ or $\mathrm{P}<0.001)$. The interaction items $\mathrm{AC}$ and $\mathrm{AD}$ and the quadratic terms $\mathrm{A}^{2}, \mathrm{~B}^{2}, \mathrm{C}^{2}$ and $\mathrm{D}^{2}$ had significant effects on response chelating rate $(\mathrm{P}<0.05$ or $\mathrm{P}<0.001)$.

\section{Response Surface Analysis}

The response surface reflects the effects of the interaction of the other factors on the H. marmoreus and Se chelation when the initial selenite concentration, chelation time, mass ratio and $\mathrm{pH}$ are 0 . The degree of steepness of the surface indicates whether the influence of different factors on the chelating rate was significant. Meanwhile, the strength of the interaction between the two factors depends on the shape of the isotypes. If the contour is elliptical, then the interaction between the two factors is strong and the impact is significant. If the contour is round, then the result is reversed. The contour sparseness reflects the strength of the influence, its closeness indicates a considerable impact on the chelating rate and the sparsity indicates minimal impact (Bonis, 1964).

The effects of the interaction of the two factors on the chelating rate are shown in Fig. 5. As shown in the Figure, the interaction between the initial mass sodium selenite concentration and $\mathrm{pH}$ (AD) had the most significant effect on the chelating rate, followed by the effect on the chelation rate of the initial mass concentration and chelation time interaction (AC). The interaction effects of mass ratio and chelation time (BC), mass ratio and $\mathrm{pH}(\mathrm{BD})$ and chelation time and $\mathrm{pH}(\mathrm{CD})$ on the chelation rate were insignificant.

\section{Optimum Process Condition Determination and Model Verification}

Design-Expert software was used to obtain the optimal process for chelating Se from PHM by analyzing the response surface. The initial mass sodium selenite concentration was $7.95 \mathrm{mg} / \mathrm{mL}$, the mass ratio was $6.11: 1$ $(\mathrm{mg} / \mathrm{mg})$, the chelation time was $6.89 \mathrm{~h}$ and the $\mathrm{pH}$ was 5.11. Under the optimized conditions, the Se of SPHM rate can reach $10.36 \%$. In verifying the accuracy of the response surface optimization model, according to convenient operation, the adjustment process parameters are as follows: The initial mass sodium selenite concentration was $8 \mathrm{mg} / \mathrm{mL}$, the ratio was $6: 1(\mathrm{mg} / \mathrm{mg})$, the chelation time was $7 \mathrm{~h}$, the $\mathrm{pH}$ was 5 and the chelating rate was $10.07 \%$. The difference between the number and our prevalue was insignificant, thereby verifying the prediction experiment reliability.

\section{Infrared Characterization of PHM and Se Chelate}

The infrared spectrum of the PHM/SPHM is shown in Fig. 6. Figure 6 reveals that the PHM infrared spectroscopy had characteristic absorption peaks of polysaccharides. The absorption peaks that appeared at the WNs of 340.3, 2931, 1635 and $1409 \mathrm{~cm}^{-1}$ were generated by stretching vibrations of $\mathrm{O}-\mathrm{H}, \mathrm{C}-\mathrm{H}, \mathrm{C}=\mathrm{O}$ and $\mathrm{C}-\mathrm{O}$ and the flexural vibrations of $\mathrm{O}-\mathrm{H}$ and $\mathrm{C}-\mathrm{H}$ increased at the absorption peaks at the WN of 1203 and $1151 \mathrm{~cm}^{-1}$. 


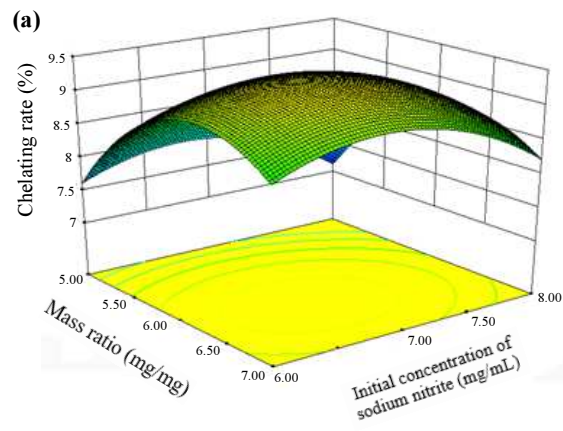

(c)
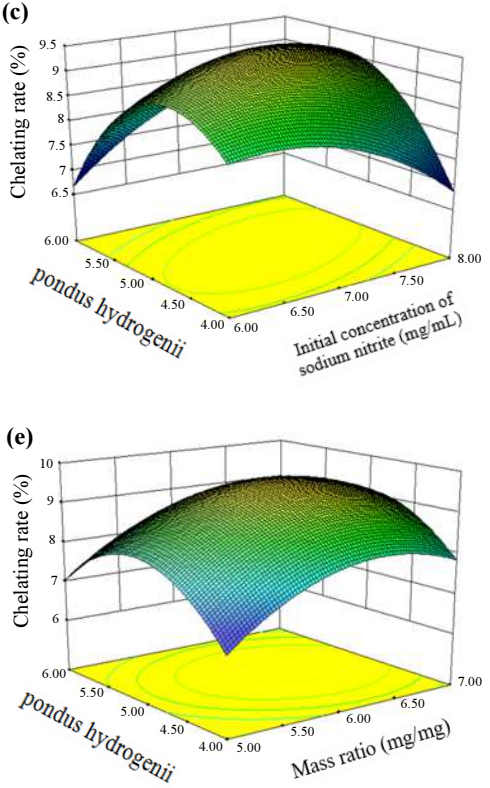

(b)

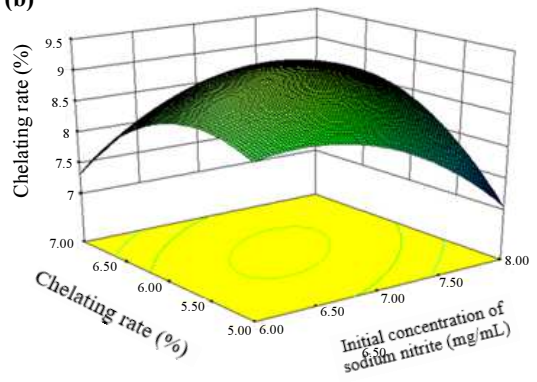

(d)

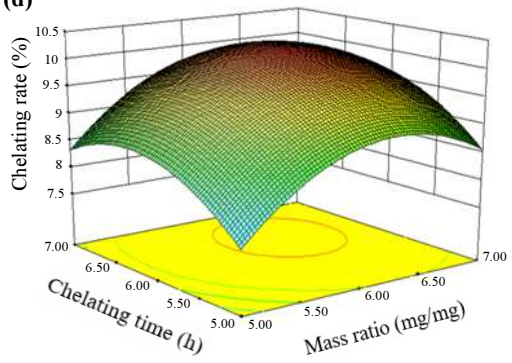

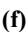

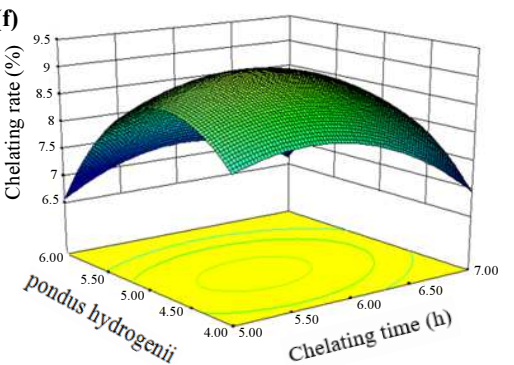

Fig. 5: Effect of interaction between two factors on chelation rate. (a) Initial sodium nitrite concentration vs. mass ratio, (b) initial sodium nitrite concentration vs. chelating time, (c) initial sodium nitrite concentration vs. $\mathrm{pH}$, (d) mass ratio vs. c chelating time, (e) mass ratio vs. $\mathrm{pH}$ and (f) chelating time vs. $\mathrm{Ph}$

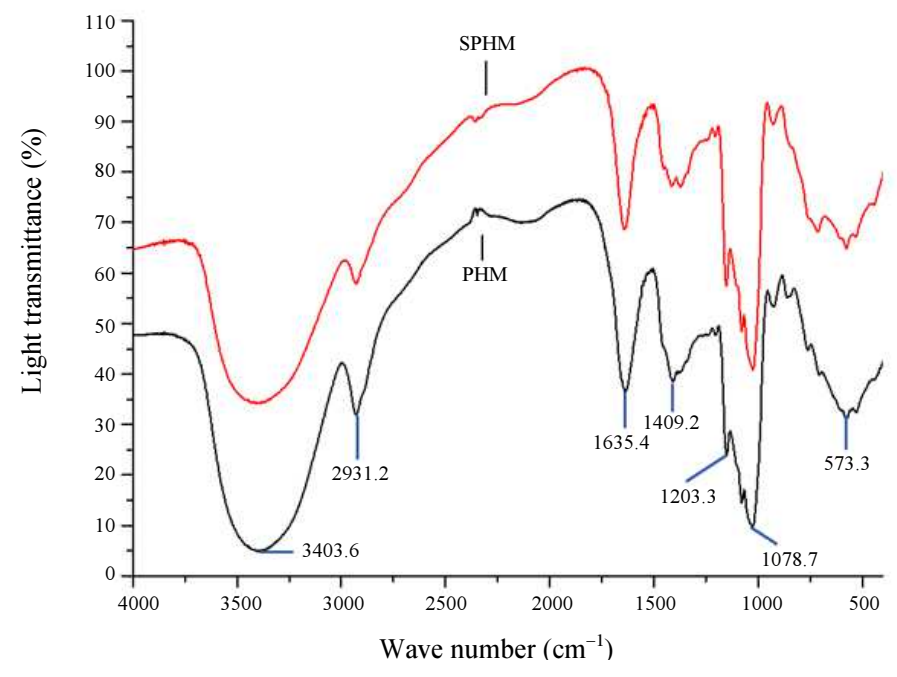

Fig. 6: Infrared spectra of PHM and SPHM 
The peaks at 1078 and $1025 \mathrm{~cm}^{-1}$ were the characteristic peaks caused by the stretching vibration of the furan nucleus and the pyran ring of the sugar, respectively. Compared with PHM, the peak shape of SPHM infrared spectrum showed insignificant change. Only the absorption wavelengths of few functional peaks showed certain bathochromic and shift. A characteristic absorption peak was observed near $923 \mathrm{~cm}^{-1}$, which was a stretching vibration of $\mathrm{Se}=\mathrm{O}$ and a peak near $717 \mathrm{~cm}^{-1}$ was a stretching vibration peak of Se-C (Franco et al., 1985). This finding indicated that sodium selenite participated in Se polysaccharide synthesis in the PHM, thereby causing the polysaccharide structure to change to some extent.
Scanning Electron Microscopic Analysis of PHM and Se Chelate

The results of scanning electron microscopy analysis of PHM and its Se chelate are shown in Fig. 7 and 8.

The PHM sample was in the form of flakes or debrislike materials. The surface structure of the polysaccharide was tight and the intermolecular force was high. The Se chelate had an irregular shape with a convex and concave surface possessing many holes. This condition indicated that a repulsive force was present between the complex molecules and the intermolecular attraction was weak (Liu et al., 2008). Further analysis was required regarding the PHM and SPHM structures.

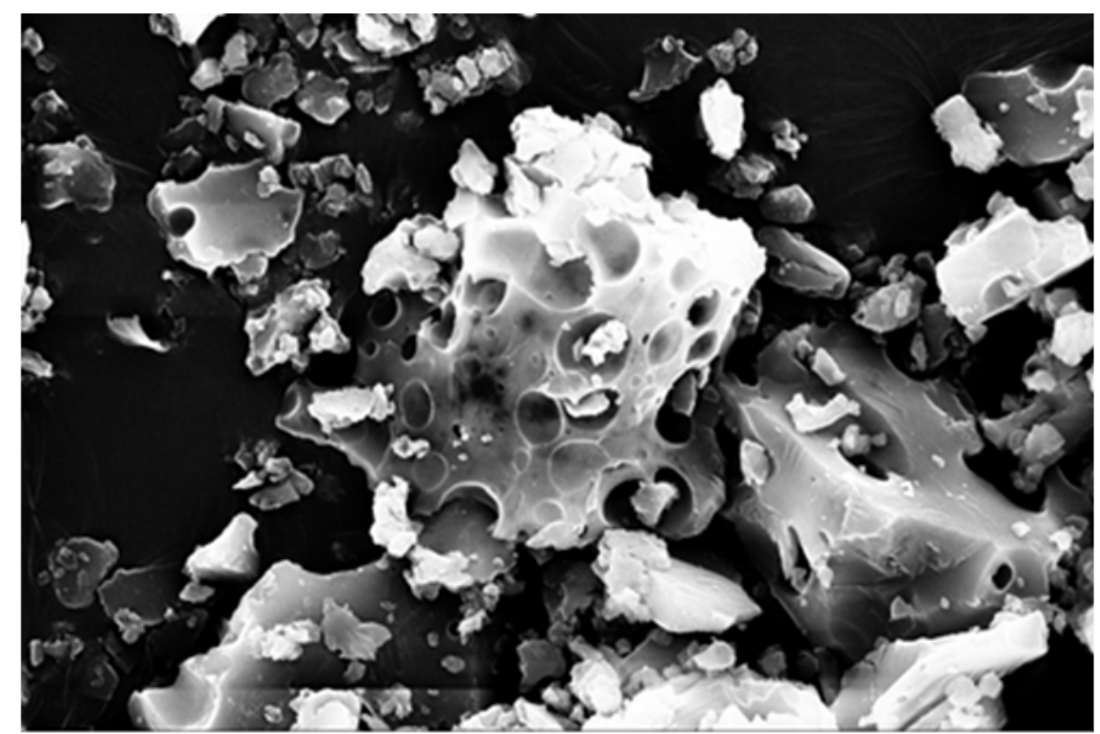

Fig. 7: Electron microscopy scan of PHM $(\times 2000)$

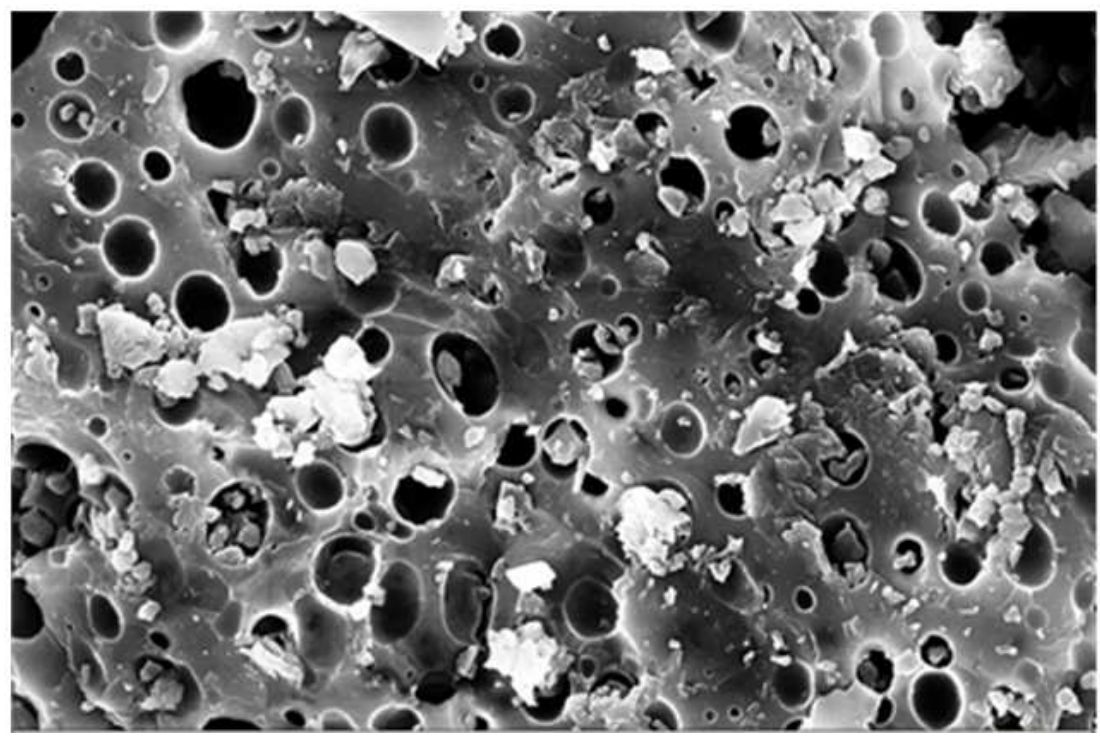

Fig. 8: Electron microscopy scan of SPHM $(\times 2000)$ 


\section{PHM and SPHM Antioxidant Activities}

\section{Scavenging Ability of DPPH Free Radicals}

The scavenging ability of DPPH free radicals before and after PHM chelating is shown in Fig. 9. PHM had a certain scavenging ability on the scavenged DPPH free radicals. With the increase in polysaccharide concentration, the scavenging rate gradually rose and tended to be stable (the ranges of up and down changes were small). Compared with the PHM, the ability of scavenged free radical of DPPH of the SPHM was enhanced. The ability of the $T$. farfara $\mathrm{L}$. Se polysaccharide-removed DPPH free radicals was significantly enhanced after selenide modification. The reason may be related to the interaction between the chelating site of $\mathrm{Se}$ ions and reactive groups of polysaccharides and the specific reasons need further study.

\section{Scavenging Ability of OH Radicals}

The scavenging ability of the $\mathrm{OH}$ radicals before and after the PHM chelation is shown in Fig. 10. The PHM had certain scavenging ability to $\mathrm{OH}$ radicals before and after chelation and the scavenging ability had a certain linear relationship with the polysaccharide concentration.

The scavenging ability of the SPHM to OH radicals was higher than that of the PHM. This result indicated that selenization modification increased the degree of the anti-oxidant activity of PHM to some extent. The specific mechanism remains to be further studied. Shang Longchen et al. found that after selenization of the C. moschata (Duch. ex Lam.) Duch. Ex Poiret polysaccharide, the scavenging effect of $C$. moschata (Duch. ex Lam.) Duch. Ex Poiret Se polysaccharide on $\mathrm{OH}$ radicals was significantly higher than that of $C$. moschata (Duch. ex Lam.) Duch. Ex Poiret polysaccharides.

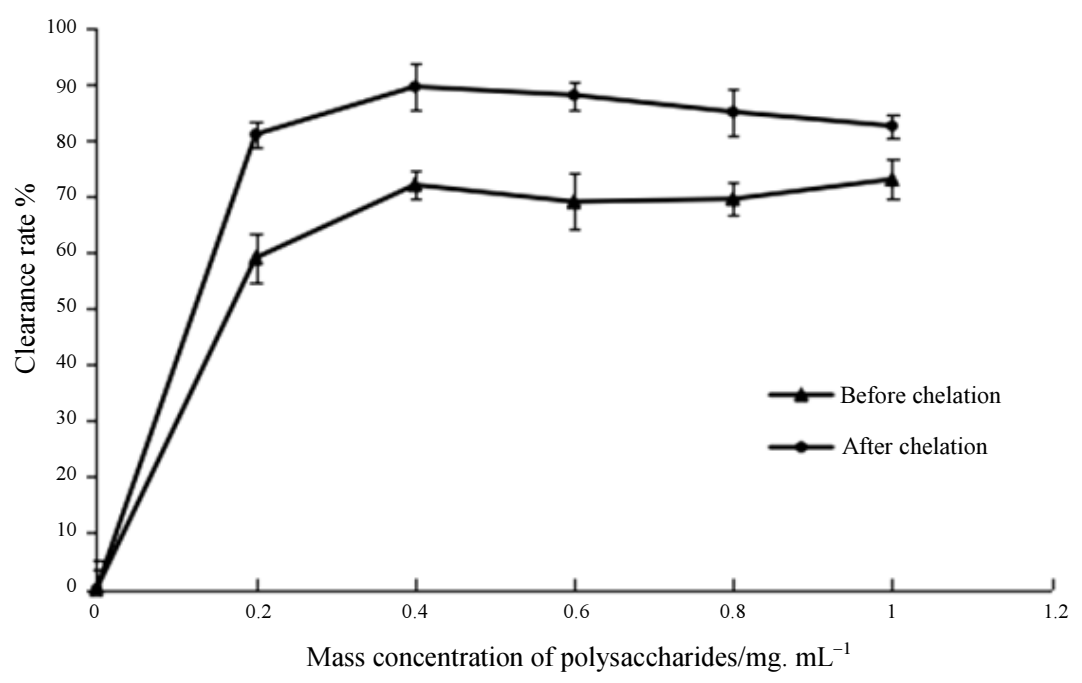

Fig. 9: DPPH free radical scavenging ability of PHM before and after chelation

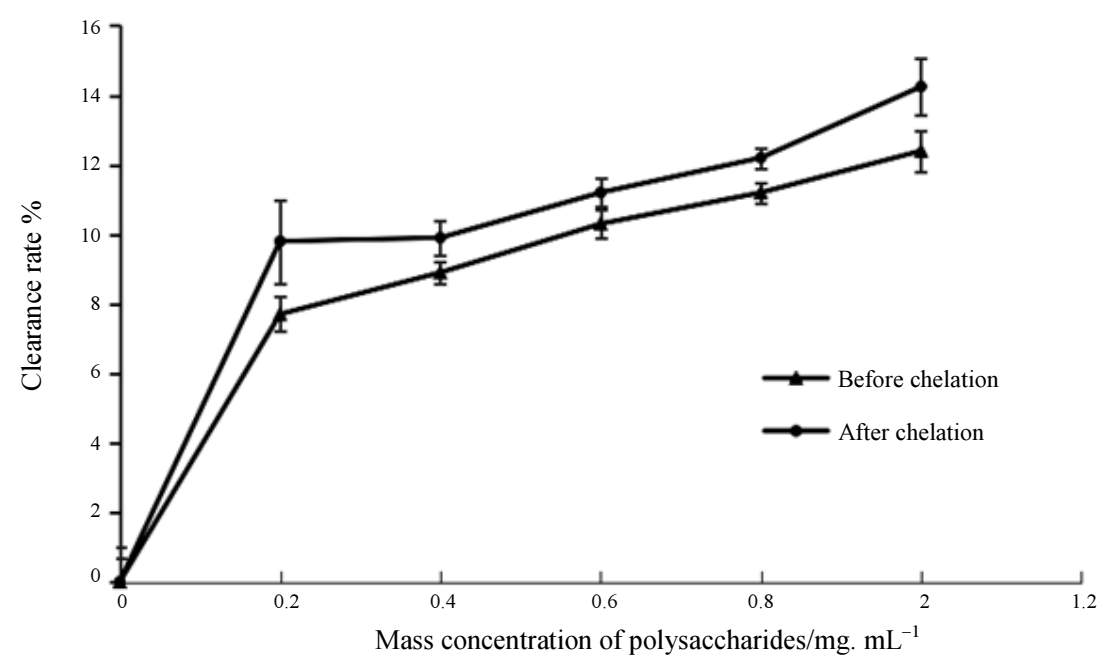

Fig. 10: Ability of scavenging $\mathrm{OH}$ free radical of PHM before and after chelation 


\section{Conclusion}

We used H. marmoreus as the raw material and the PHM was extracted by water extraction and alcohol sedimentation. The optimal chelation process conditions, that is, the initial mass sodium selenite concentration, of PHM, were determined by the response surface method. The ratio was $7.95 \mathrm{mg} / \mathrm{mL}$, the mass ratio was $6.11: 1(\mathrm{mg} / \mathrm{mg})$, the chelation time was $6.89 \mathrm{~h}$ and the $\mathrm{pH}$ was 5.11. Under optimized conditions, the chelating rate of the $H$. marmoreus polysaccharide and Se reached $10.36 \%$. Compared with PHM, the antioxidative activity of the SPHM was further enhanced. In this study, the PHM was chelated with Se and the PHM was successfully selenized. The antioxidant activity of the SPHM was considerably improved to some extent and the mechanism of activity enhancement still needs further research. The research results provided a theoretical basis for the SPHM as a new type of functional food antioxidant, thereby laying a foundation for the promotion of the added value of $H$. marmoreus resources.

\section{Author's Contributions}

Ting Liu: Paricipated in all experiments and article writing; also responsible for data analysis.

Xue Jiang: Paricipated in some experiments and data analysis.

Wei Wang: Paricipated in some experiments and data proceessing.

Bing Xu: Paricipated in project design and article writing; responsibilites of contacts for research materials.

\section{Ethics}

This article is original and contains unpublished material. The corresponding author confirms that all of the other authors have read and approved the manuscript and no ethical issues involved.

\section{References}

Bonis, L.J., 1964. Surface analysis-interdisciplinary aspects of surface phenomena. Ind. Eng. Chem., 56: 40-43. DOI: $10.1021 /$ ie $50655 \mathrm{a} 007$

Franco, C., A.D. Francesco, D. Angelo, I. Francesco and V. Gaetano et al., 1985. NH stretching vibrations of 5,5-dimethylimidazolidines with $\mathrm{O}, \mathrm{S}$ or Se at $\mathrm{C}-2$ and C-4. Spectrochimica Acta Part A: Molecular Spectroscopy, 41: 487-490.

DOI: $10.1016 / 0584-8539$ (85)80155-0

Gaiyan, L.I., X. Liu and L. Zhang, 2016. Preparation of coltsfoot polysaccharide functional beverage and determination of anti-oxidation ability. Northwest Pharmaceutical J., 31: 399-402.
Gharzouli, K., S. Khennouf, S. Amira and G. Akila, 1999. Effects of aqueous extracts from quercus ilex 1 . root bark, punica granatum 1. fruit peel and artemisia herba-alba asso leaves on ethanol-induced gastric damage in rats. Phytotherapy Res., 13: 42-45.

DOI: $10.1002 /(\mathrm{SICI}) 1099-1573 \quad$ (199902)13:1<42: AID-PTR383>3.0.CO;2-2

Haitao, L.V., D. Ke and S. Hu, 2018. Selenylation modification of degraded polysaccharide from enteromorpha prolifera and its biological activities. J. Ocean University China, 17: 445-450. DOI: $10.1007 / \mathrm{s} 11802-018-3296-1$

Harada, A., S. Gisusi and S. Yoneyama, 2005. Effects of strain on the taste of bunashimeji mushrooms (Hypsizygus marmoreus) in sensory evaluation and taste component analysis. Rinsan Shikenj Oha/J. Hokkaido Forest Products Res. Institute, 19: 25-30.

Hirayama, O. and M. Yida, 1997. Evaluation of hydroxyl radical-scavenging ability by chemiluminescence. Analytical Biochem., 251: 297-299. DOI: 10.1006/abio.1997.2282

Huang, L., M. Chen, S. Li and N.P. Shah, 2015. Antioxidant activities and bifidogenic properties of water-soluble crude polysaccharide preparations from flammulina velutipes and hypsizygus marmoreus mushrooms. Int. J. Probiotics Prebiotics, 10: 37-42.

Kumar, M.G.M. and B. Satheesan, 2010. Physiological activity of energy plants fertilized with sevage sludge and usefulness of the Phytotoxkit test in practice. Environ. Protection Eng., 36: 73-81.

Li, C.C., L.Z. Guo and W.D. Lu, 2009. Identification of Hypsizygus marmoreus strains using RAPD and SRAP molecular markers. ACTA Edulis Fungi.

Li, E.X., Y.Q. Huang, M.Y. Jiang, M. Fang and C.X. Fu, 2010. ISSR analysis of genetic diversity of lilium brownii var. viridulum baker in jiangxi province. ACTA Horticulturae Sinica, 37: 811-816.

Lingyun, R., 2014. Characteristics of mycelial growth and enzyme production of Hypsizygus marmoreus under different nutritional conditions. Mycosystema, 3: 697-705.

Liu, M., S. Li, X. Wang, Z. Yongfa and Z. Jianjun et al., 2018. Characterization, anti-oxidation and antiinflammation of polysaccharides by Hypsizygus marmoreus against LPS-induced toxicity on lung. Int. J. Biol. Macromolecules, 111: 121-128.

DOI: 10.1016/j.ijbiomac.2018.01.010

Liu, M., Z. Feng and G. Huo, 2008. Mating type factors of hypsizygus marmoreus. ACTA Edulis Fungi, 15: $17-19$.

Malgorzata, B., K. Piotr and N. Jacek, 2012. The properties, functions and use of selenium compounds in living organisms. J. Environ. Sci. Health. Part C: Environ. Carcinogenesis Reviews, 30: 225-252. DOI: 10.1080/10590501.2012.705164 
Rayman, M.P., 2000. The importance of selenium to human health. Lancet, 356: 233-241. DOI: 10.1016/S0140-6736 (00)02490-9

Schmidbaur, H. and K.H. Mitschke, 1971. Hydrogendicarboxylate ions as hydrogen bonded chelate systems in organoantimony compounds. Angewandte Chemie Int. Edition, 10: 136-137.

Selvi, N.A.T., P. Jansirani, L. Pugalendhi and A. Nirmalakumari, 2012. Per se performance of genotypes and correlation analysis in Pumpkin (Cucurbita moschata Duch. ex Poir). Electronic J. Plant Breeding, 3: 987-994.

Song, F.Q., Y. Liu, X.S. Kong, W. Chang and G. Song, 2013. Progress on understanding the anticancer mechanisms of medicinal mushroom: Inonotus obliquus. Asian Pac. J. Cancer Prev., 14: 1571-1578. DOI: 10.7314/APJCP.2013.14.3.1571

Sui, H., X. Li, Y. Zhao and W. Wang, 2004. The antioxidation effect of total flavonoid extract in taraxacum mongolicum hand-mazz on the brain of ageing model mice induced by d-galactose. Heilongjiang Med. Pharmacy, 27: 3-4.

Suja, K.P., A. Jayalekshmy and C. Arumughan, 2004. Free radical scavenging behavior of antioxidant compounds of sesame (sesamum indicum 1.) in DPPH system. J. Agric. Food Chem., 52: 912-915. DOI: $10.1021 / \mathrm{jf0303621}$

Tao, M.X., W. Wang and X.W. Wang, 2007. Analysis of nutrient components and bioactive substance of hypsizygus marmoreus and study on activity of polysaccharides scavenging free radicals. Food Sci., 28: 404-407.

Xing, Z., Y. Wang, Z. Feng, Z. Zhihui and L. Xinghua, 2007. Effect of 60Co-irradiation on postharvest quality and selected enzyme activities of hypsizygus marmoreus fruit bodies. J. Agric. Food Chem., 55: 8126-8132. DOI: 10.1021/jf070941w

Xue, X., K. Hanna, C. Despas, W. Feng and D. Nansheng, 2009. Effect of chelating agent on the oxidation rate of PCP in the magnetite $/ \mathrm{H}_{2} \mathrm{O}_{2}$ system at neutral pH. J. Molecular Catalysis A: Chemical, 311: 29-35. DOI: 10.1016/j.molcata.2009.06.016
Yasukawa, K., T. Aoki, M. Takido, I. Tetsuro and S. Hideharu et al., 1994. Inhibitory effects of ergosterol isolated from the edible mushroom Hypsizygus marmoreus on TPA-induced inflammatory ear oedema and tumour promotion in mice. Phytotherapy Res., 8: 10-13.

DOI: $10.1002 /$ ptr.2650080103

Zhang, J., H. Chen, M. Chen, R. Ang and H. Jianchun et al., 2015a. Cloning and functional analysis of a laccase gene during fruiting body formation in Hypsizygus marmoreus. Microbiological Res., 179: 54-63. DOI: 10.1016/j.micres.2015.06.005

Zhang, L., Z.H. Li, Z.J. Dong, L. Yan and L. Ji-Kai, 2015b. A viscidane diterpene and polyacetylenes from cultures of Hypsizygus marmoreus. Natural Products Bioprospecting, 5: 99-103. DOI: $10.1007 / \mathrm{s} 13659-015-0058-2$

Zhang, J., H. Chen, M. Chen, W. Hong and S. Xiaoxia et al., 2017a. Construction and application of a gene silencing system using a dual promoter silencing vector in Hypsizygus marmoreus. J. Basic Microbiology, 57: 78-86. DOI: 10.1002/jobm.201600291

Zhang, J.J., H. Chen, M.Y. Xie, C. Ming-Jie and H. HaiBo et al., 2017b. Mechanism of glucose regulates the fruiting body formation in the beech culinarymedicinal mushroom, Hypsizygus marmoreus (agaricomycetes). Int. J. Med. Mushrooms, 19: 179189. DOI: 10.1615/IntJMedMushrooms.v19. i2.100

Zhu, Z.Y., F. Liu, H. Gao, S. Huiqing and M. Meng et al., 2016. Synthesis, characterization and antioxidant activity of selenium polysaccharide from Cordyceps militaris. Int. J. Biol. Macromolecules, 93: 1090-1099.

DOI: $10.1016 /$ j.ijbiomac.2016.09.076 